\title{
Foot Pathology in Patients with Paget's Disease of Bone
}

\author{
Anita E. Williams, BSc(Hons) ${ }^{\star} \dagger$ \\ Terence W. O'Neill, MD‡ \\ Sylvia Mercer, BSc(Hons)‡ \\ Brigitte Toro, PhD十§ \\ Christopher J. Nester, PhD†
}

The characteristic bone deformities associated with advanced Paget's disease of bone may result in abnormal gait and plantar foot pressures, which contribute to the development of pressure-related skin problems. This study aimed to characterize the foot problems and foot-care needs in this patient group and to investigate the effect of disease distribution on the occurrence of foot pathology. One hundred thirty-four patients with Paget's disease were assessed clinically, and the Foot Structure Index was completed for each patient. Patients completed self-administered questionnaires concerning foot function (Foot Function Index) and quality of life (12-Item Short Form). The results of this study suggest that foot-health and footwear problems are common in patients with Paget's disease. Forty percent of the patients required professional foot care in addition to those already receiving it. The site of pagetic involvement did not affect the occurrence of foot pathology. Further research is required on the impact of the extent of any femoral or tibial deformity on foot symptoms and pathology. Biomechanical studies of the forces and motion in the foot related to different degrees of femoral and tibial deformity might also help determine the impact of deformity on foot pathology. ( $\mathrm{J}$ Am Podiatr Med Assoc 96(3): 226-231, 2006)

Paget's disease of bone is a focal disorder characterized by rapid bone remodeling and the formation of structurally abnormal bone. The most frequently affected bones are the pelvis, femur, spine, and skull. ${ }^{1}$ In patients with advanced disease, characteristic bone deformities may occur, which may result in the development of pressure-related skin problems, such as hyperkeratosis (including calluses and corns),

*Department of Podiatry, University of Salford, Salford, England.

$\dagger$ Centre for Rehabilitation and Human Performance Research, University of Salford, Salford, England.

\$Department of Rheumatology, Hope Hospital, Salford, England.

$\S$ Department of Physiotherapy, University of Salford, Salford, England.

Corresponding author: Anita E. Williams, BSc(Hons), Directorate of Podiatry, University of Salford, Frederick Rd, Salford, England M6 6PU. and symptoms of foot pain. Little is known, however, about the occurrence of foot pathology in patients with Paget's disease. The aim of this study was to characterize foot problems and foot-care needs in a series of patients with Paget's disease. We also investigated the effect of disease distribution on the occurrence of foot pathology.

\section{Methods}

\section{Participants}

One hundred thirty-four patients with Paget's disease were systematically recruited from attendees at the specialist outpatient clinics at Hope Hospital, Salford, England. All of the patients were assessed clinically by an experienced podiatrist who also complet- 
ed the Foot Structure Index ${ }^{2}$ for each patient. Patients completed self-administered questionnaires concerning foot function (Foot Function Index) ${ }^{3}$ and quality of life (12-Item Short Form). ${ }^{4}$ The site of Paget's disease involvement was determined from skeletal scintigrams performed at previous clinical visits. The researcher was blind to the site of the Paget's disease at the time of the clinical assessment, although inevitably the physical appearance of the lower limb may have unblinded the researcher during some assessments. The study received approval from the Salford and Trafford ethics committee.

\section{Clinical Assessment}

The foot assessment included evaluation for the presence and site of hyperkeratosis (Fig. 1) and abnormalities of the nails. Simple clinical observations such as these have been found to be highly reliable when performed by foot-care specialists. ${ }^{5}$ A subjective assessment of each patient's need for foot care was made on the basis of the clinical examination data. Patients were considered to require foot care if they presented with pathologic nails, such as thickened nails, that the patient reported as being unmanageable; if they had painful hyperkeratosis (corns or calluses); or if their foot health might improve with the use of orthoses or specialized footwear. Patients were not considered to require foot care if they could manage reduction of their own nails or had painless hyperkeratosis or if the provision of foot orthoses and specialized footwear was deemed unlikely to improve their foot health. Subjects were asked whether they experienced foot pain (yes/no) and the site of pain (plantar heel, plantar metatarsal, or toes).

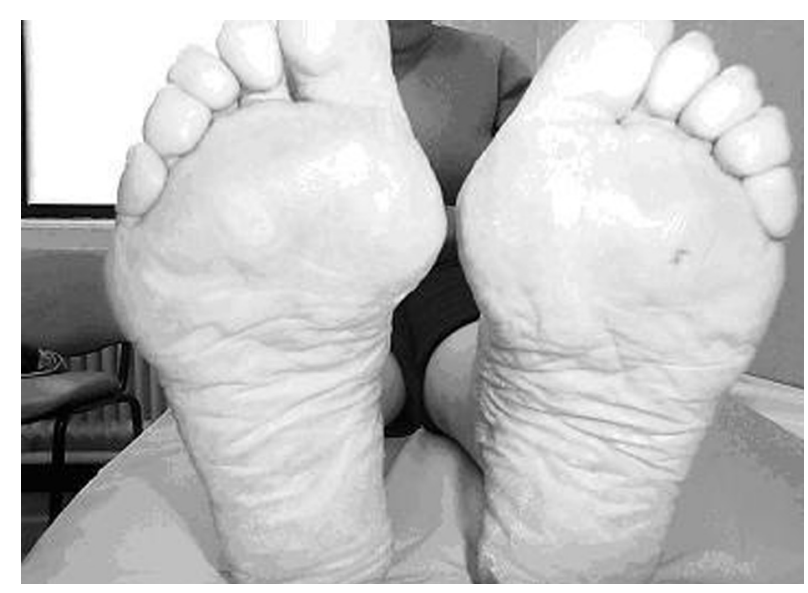

Figure 1. Hyperkeratosis (callus) under the forefoot.
Suitability of footwear was determined on the basis of factors such as shoe type (eg, court shoe or lace-up shoe), heel height, heel counter stiffness, fastener type, and sole type (eg, shock-absorbing or thin). If at least one of these factors was considered inappropriate for the patient, then the footwear was recorded as being unsuitable. These factors have also been used as components of a Footwear Assessment Form ${ }^{6}$ designed to measure footwear suitability in older adults. Patients were considered to need prescription footwear if they were having difficulty with the fit of retail footwear because of the width and depth of the upper. Patients were considered to need foot orthoses if they had a functional foot problem, such as excessive lowering of the arch, leading to instability or a rigid foot deformity that required pressure redistribution.

The Foot Structure Index ${ }^{2}$ was used to indicate the degree of foot deformity. It includes an assessment of whether there is evidence of hallux valgus, lesser-toe deformities, excessive pronation/supination, and abnormal range of motion at the ankle joint. Higher scores indicate greater deformity, and the scores range from 0 to 200 . The Foot Structure Index has primarily been used in patients with rheumatoid arthritis, and although it has not been validated for use in patients with Paget's disease, no viable alternative specific to Paget's disease was available.

The Foot Function Index is a self-administered questionnaire consisting of 23 items grouped in three domains: foot pain (9 items), disability (9 items), and functional limitation (5 items). ${ }^{3}$ All of the items are rated using 100-mm visual analog scales, and higher scores indicate greater pain, disability, and limitation of activity, and thus poorer foot health. To obtain a domain score, the item scores are totaled and then divided by the maximum total possible for all of the domain items that the patient indicated were applicable. If a subject indicates that he or she did not perform an activity such as wearing an orthotic device, then that item is marked as not applicable and is excluded from the total possible. To eliminate the decimal point, the score for each domain is multiplied by 100. Therefore, domain scores range from 0 to 100 , with higher scores indicating greater impairment. A total foot function score is derived by calculating the average of the three domain scores. Although this tool has been validated for patients with rheumatoid arthritis, the Foot Function Index was used here because no viable alternative specific to Paget's disease was available.

Patients completed the 12-Item Short Form, ${ }^{4}$ which comprises 12 questions and two component scores in physical and mental domains (six questions in 
each). The subgroup scores range from 0 to 100, with higher scores indicating worse quality of life.

\section{Data Analysis}

Differences in foot function (Foot Function Index), foot structure (Foot Structure Index), and quality of life (12-Item Short Form) between men and women were determined using Mann-Whitney $U$ tests. To determine the effect of the site of Paget's disease, patients were separated into three groups: those with disease in the lower limb, ie, femur, tibia, or foot (site 1); those with disease in the pelvis or any part of the upper body only (site 2); and those with disease in the lower limb plus evidence of disease at other sites (site 3). The Kruskal-Wallis test was performed to explore the impact of the three Paget's disease sites on levels of foot function, deformity, and quality of life as measured using the Foot Function Index, the Foot Structure Index, and the 12-Item Short Form, respectively. Differences in the frequency of hyperkeratosis and foot pain in the three sites were determined using $\chi^{2}$ tests. The significance level for all of the statistical tests was set at $P<.05$.

\section{Results}

\section{Patients}

The mean patient age was 74.5 years (range, $46-91$ years). There were 70 women and 64 men. Eighteen patients had evidence of disease in the lower limb (site 1), 58 had disease affecting the pelvis/upper body (site 2), and 51 had disease in the lower limb and at other sites (site 3). Seven patients could not be assigned to a Paget's disease group because of the absence of skeletal scintigrams; therefore, the results from these patients were used only in the total sample statistics.

\section{Clinical Assessment}

Eight percent of the total number of patients (127) had evidence of hyperkeratosis on the medial border of the heel, with a similar proportion in men and women. However, there was evidence of a sex effect on the occurrence of hyperkeratosis in the plantar metatarsal area. Of the 69 patients presenting with corns and calluses under the forefoot, $77 \%$ were women and $23 \%$ were men $(P=.01)$. Similarly, there was evidence of a sex effect on the occurrence of corns on the toes. Of 33 patients with this condition, $79 \%$ were women and $21 \%$ were men $(P<.0005)$.
There was no sex difference in reported pain in the heel or in the toes.

Seventy-three patients had received professional foot care in the past or were currently receiving professional National Health Service or private foot care. Of the remaining 61 patients, 49 may have (as assessed by the podiatrist) benefited from professional foot care. Only 12 patients required no footcare intervention at all. The foot care required was principally management of hyperkeratotic lesions or foot pain.

There was little evidence of use of foot orthoses, although this intervention could have benefited 19\% of the patients (as assessed by the podiatrist in relation to abnormal foot structure or function). In the entire sample, only two patients were wearing prescribed specialized footwear, although another six patients could have benefited. The remainder of the patients (125) wore nonspecialized retail footwear, and in $29 \%$ of these patients, the footwear was assessed as being unsuitable. Eighty percent of those wearing unsuitable footwear were women (Fig. 2). Three patients had outer-sole rise adaptations to their retail footwear (Fig. 3), and another eight required an outer-sole rise to their own footwear or specialized footwear.

The mean (SD) Foot Function Index, Foot Structure Index, and 12-Item Short Form scores in men and women are given in Table 1 . There were no significant sex differences in any of these measures. The frequency of foot pathology (including calluses, corns, and pain) and the need for foot care, orthoses, and footwear interventions in patients with Paget's disease in the lower limb only (site 1), in the pelvis and upper limb only (site 2), and in both upper and lower limbs (site 3) are given in Table 2. There were no statistically significant differences in the occur-

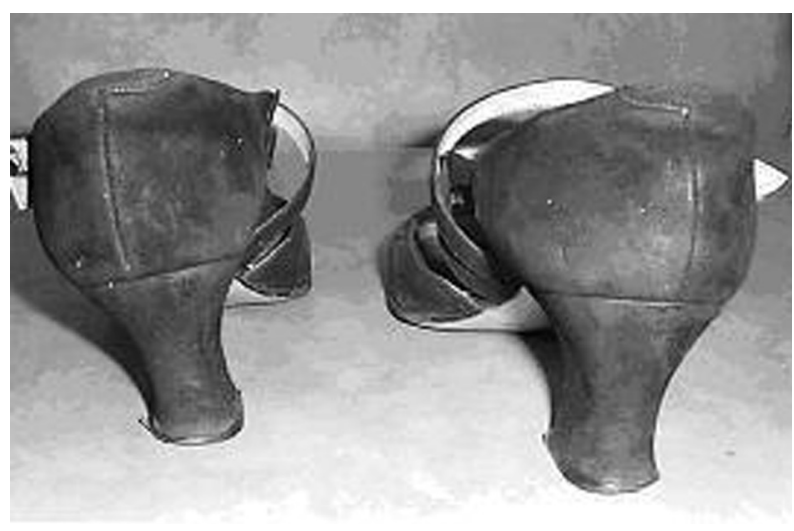

Figure 2. Example of unsuitable footwear. 


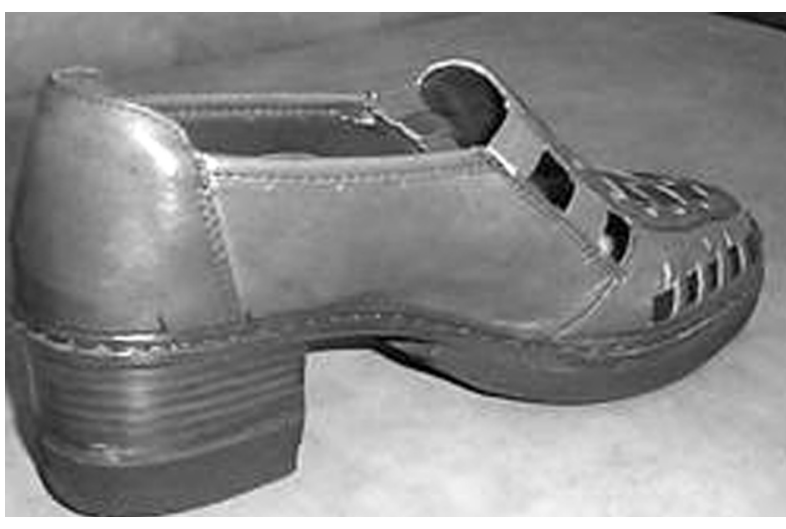

Figure 3. Outer-shoe rise as management for a leglength difference created by Paget's disease involvement in the lower limb.

rence of foot pathology or foot-care needs among the three groups.

The mean (SD) Foot Function Index, Foot Structure Index, and 12-Item Short Form scores by Paget's disease site are given in Table 3 . There were no statistically significant differences in the mean values among the three groups.

\section{Discussion}

These data suggest that foot problems are common in patients with Paget's disease. There was, however, no important effect of the site of pagetic involvement on the occurrence of foot pathology, foot function as measured using the Foot Function Index, or foot deformity as measured using the Foot Structure Index. Calluses and corns were more frequent in women than in men. This is in keeping with findings from previous literature. ${ }^{7}$ Ill-fitting shoes have been highlighted as a contributing factor to the development of foot problems, particularly in females. ${ }^{8}$ This was supported by our findings. However, the presence of corns and calluses or ill-fitting shoes did not seem to affect levels of foot function, foot deformity, or quality of life in this patient group.

This study was a descriptive survey, and we did

\begin{tabular}{|c|c|c|c|c|c|}
\hline & All Patients & Men & Women & $Z^{a}$ & $P$ Value $^{a}$ \\
\hline $\begin{array}{l}\text { FFI-pain subscore } \\
\text { Mean (SD) } \\
\text { Range } \\
\text { Median }\end{array}$ & $\begin{array}{c}20.5(29.5) \\
0-100 \\
0\end{array}$ & $\begin{array}{c}23.4(32.7) \\
0-100 \\
0\end{array}$ & $\begin{array}{c}17.8(26.1) \\
0-100 \\
0\end{array}$ & -0.471 & .637 \\
\hline $\begin{array}{l}\text { FFI-disability subscore } \\
\text { Mean (SD) } \\
\text { Range } \\
\text { Median }\end{array}$ & $\begin{array}{c}20.2(27.2) \\
0-100 \\
4\end{array}$ & $\begin{array}{c}19.6(25.6) \\
0-100 \\
4\end{array}$ & $\begin{array}{c}20.7(28.8) \\
0-99 \\
4\end{array}$ & -0.121 & .904 \\
\hline $\begin{array}{l}\text { FFI-limitations subscore } \\
\text { Mean (SD) } \\
\text { Range } \\
\text { Median }\end{array}$ & $\begin{array}{c}10.1(18.3) \\
0-100 \\
0\end{array}$ & $\begin{array}{c}10.6(18.7) \\
0-100 \\
0\end{array}$ & $\begin{array}{c}9.6(18.1) \\
0-80 \\
0\end{array}$ & -0.125 & .901 \\
\hline $\begin{array}{l}\text { FFI-total score } \\
\text { Mean (SD) } \\
\text { Range } \\
\text { Median }\end{array}$ & $\begin{array}{c}17.4(21.9) \\
0-80 \\
6\end{array}$ & $\begin{array}{c}18.2(22.6) \\
0-80 \\
8\end{array}$ & $\begin{array}{c}16.7(21.4) \\
0-77 \\
2\end{array}$ & -0.193 & .847 \\
\hline $\begin{array}{l}\text { FSI score } \\
\text { Mean (SD) } \\
\text { Range } \\
\text { Median }\end{array}$ & $\begin{array}{c}6.7(4.3) \\
0-19 \\
6\end{array}$ & $\begin{array}{c}6.2(4.3) \\
0-19 \\
6\end{array}$ & $\begin{array}{c}7.1(4.3) \\
0-16 \\
7\end{array}$ & -1.277 & .202 \\
\hline $\begin{array}{l}\text { SF-12-mental subscore } \\
\text { Mean (SD) } \\
\text { Range } \\
\text { Median }\end{array}$ & $\begin{array}{l}44.6(11.6) \\
19-70 \\
45\end{array}$ & $\begin{array}{c}45.0(12.0) \\
19-65 \\
44\end{array}$ & $\begin{array}{c}44.2(11.3) \\
20-70 \\
45\end{array}$ & -0.571 & .568 \\
\hline $\begin{array}{l}\text { SF-12-physical subscore } \\
\text { Mean (SD) } \\
\text { Range } \\
\text { Median }\end{array}$ & $\begin{array}{c}33.8(10.3) \\
17-60 \\
32\end{array}$ & $\begin{array}{c}34.9(10.8) \\
17-60 \\
34\end{array}$ & $\begin{array}{c}32.7(9.8) \\
17-54 \\
32\end{array}$ & -1.140 & .254 \\
\hline
\end{tabular}

Abbreviations: FFI, Foot Function Index; FSI, Foot Structure Index; SF-12, 12-Item Short Form. aBy Mann-Whitney $U$ test (2-tailed). 
Table 2. Effect of Paget's Disease Site on the Occurrence of Foot Pathology and Requirements of Intervention

\begin{tabular}{llccc}
\hline & $\begin{array}{c}\text { Site 1 } \\
(\mathrm{n}=18)\end{array}$ & $\begin{array}{c}\text { Site 2 } \\
(\mathrm{n}=58)\end{array}$ & $\begin{array}{c}\text { Site 3 } \\
(\mathrm{n}=51)\end{array}$ & $\begin{array}{c}P \\
\text { Value }^{a}\end{array}$ \\
\hline Sex (M/F) & $9 / 9$ & $32 / 26$ & $25 / 26$ & .80 \\
Calluses on heel & $2(11)$ & $5(9)$ & $3(6)$ & .75 \\
Calluses under forefoot & $5(28)$ & $23(40)$ & $20(39)$ & .64 \\
Corns under forefoot & $2(11)$ & $12(21)$ & $7(14)$ & .49 \\
Corns on toes & $4(22)$ & $18(31)$ & $11(22)$ & .49 \\
Pain under forefoot & $7(39)$ & $15(26)$ & $12(24)$ & .44 \\
Pain on toes & $4(22)$ & $12(21)$ & $11(22)$ & .99 \\
Require foot care & $6(33)$ & $23(40)$ & $18(35)$ & .67 \\
Require foot orthoses & $5(28)$ & $11(19)$ & $8(16)$ & .30 \\
Footwear unsuitable & $3(17)$ & $14(24)$ & $16(31)$ & .91 \\
Require prescription & $1(6)$ & $2(3)$ & $1(2)$ & .66 \\
$\quad$ & & & &
\end{tabular}

Note: Data are given as number (percentage). See the text for descriptions of the sites.

${ }^{a} \mathrm{By} \chi^{2}$ test among all three Paget's disease sites.

not have a comparison group of nonpagetic patients. We cannot, therefore, determine the effect of Paget's disease on the occurrence of foot problems. Our results in relation to the occurrence of foot problems are broadly similar to findings from previous popula- tion surveys of older individuals. ${ }^{9,} 10$ Indeed, a previous study ${ }^{11}$ investigated foot problems in a healthy elderly population $(\mathrm{N}=135)$ and found that $31 \%$ of the patients presented with plantar hyperkeratosis, which was comparable to the $36 \%$ of patients found in the present study. In the same study, $21 \%$ of patients reported foot pain. In our study, pain in the forefoot was reported by $39 \%$ (site 1), $26 \%$ (site 2), and $24 \%$ (site 3) of patients. This compares with the self-administered Foot Function Index pain subscale scores reported by $25 \%$ (site 1), $21 \%$ (site 2), and 21\% (site 3) of patients.

Self-reported foot pain may be underreported because many older people do not volunteer foot pain as a problem when surveyed. ${ }^{7}$ However, in a recent study, ${ }^{12}$ foot pain was assessed as part of a validated podogeriatric assessment, and $74.6 \%$ of 1,000 patients older than 65 years reported a history of foot pain. The high number in this study may be because the patients were asked about past and current pain, and the patients included in the study had foot problems associated with chronic risk diseases, such as peripheral arterial disease. There are no population data among older people concerning the Foot Structure Index and the Foot Function Index to allow direct comparison of our results.

\begin{tabular}{|c|c|c|c|c|c|}
\hline & Site 1 & Site 2 & Site 3 & $\chi^{2} 2$ & $P$ Value $^{a}$ \\
\hline $\begin{array}{l}\text { FFI-pain subscore } \\
\text { Mean (SD) } \\
\text { Range }\end{array}$ & $\begin{array}{c}n=17 \\
24.5(30.2) \\
0-84\end{array}$ & $\begin{array}{c}n=53 \\
21.1(30.4) \\
0-100\end{array}$ & $\begin{array}{c}\mathrm{n}=48 \\
21.1(30.5) \\
0-95\end{array}$ & 0.270 & .874 \\
\hline $\begin{array}{l}\text { FFI-disability subscore } \\
\text { Mean (SD) } \\
\text { Range }\end{array}$ & $\begin{array}{c}n=17 \\
27.4(32.3) \\
0-100\end{array}$ & $\begin{array}{c}\mathrm{n}=53 \\
22.2(29.3) \\
0-99\end{array}$ & $\begin{array}{c}\mathrm{n}=48 \\
16.3(23.1) \\
0-87\end{array}$ & 0.811 & .667 \\
\hline $\begin{array}{l}\text { FFI-limitations subscore } \\
\text { Mean (SD) } \\
\text { Range }\end{array}$ & $\begin{array}{c}n=17 \\
15.6(25.5) \\
0-100\end{array}$ & $\begin{array}{c}\mathrm{n}=53 \\
12.0(20.1) \\
0-80\end{array}$ & $\begin{array}{c}\mathrm{n}=48 \\
6.7(12.3) \\
0-60\end{array}$ & 1.868 & .393 \\
\hline $\begin{array}{l}\text { FFI-total score } \\
\text { Mean (SD) } \\
\text { Range }\end{array}$ & $\begin{array}{c}\mathrm{n}=17 \\
23.4(26.3) \\
0-80\end{array}$ & $\begin{array}{c}\mathrm{n}=53 \\
18.9(23.2) \\
0-77\end{array}$ & $\begin{array}{c}\mathrm{n}=48 \\
14.7(18.9) \\
0-80\end{array}$ & 0.877 & .645 \\
\hline $\begin{array}{l}\text { FSI-total score } \\
\text { Mean (SD) } \\
\text { Range }\end{array}$ & $\begin{array}{c}n=18 \\
6.9(4.2) \\
0-15\end{array}$ & $\begin{array}{c}\mathrm{n}=57 \\
6.1(4.4) \\
0-16\end{array}$ & $\begin{array}{c}\mathrm{n}=51 \\
7.4(4.1) \\
0-19\end{array}$ & 2.790 & .248 \\
\hline $\begin{array}{l}\text { SF-12-mental subscore } \\
\text { Mean (SD) } \\
\text { Range }\end{array}$ & $\begin{array}{c}n=17 \\
45.3(12.7) \\
21-62\end{array}$ & $\begin{array}{c}n=54 \\
42.9(11.1) \\
19-61\end{array}$ & $\begin{array}{c}n=48 \\
45.9(11.8) \\
20-70\end{array}$ & 2.045 & .36 \\
\hline $\begin{array}{l}\text { SF-12-physical subscore } \\
\text { Mean (SD) } \\
\text { Range }\end{array}$ & $\begin{array}{c}\mathrm{n}=17 \\
35.7(9.8) \\
22-55\end{array}$ & $\begin{array}{c}\mathrm{n}=54 \\
31.3(10.2) \\
17-56\end{array}$ & $\begin{array}{c}n=48 \\
35.3(10.3) \\
21-60\end{array}$ & 5.190 & .075 \\
\hline
\end{tabular}

Abbreviations: FFI, Foot Function Index; FSI, Foot Structure Index; SF-12, 12-Item Short Form. Note: See the text for descriptions of the sites.

${ }^{a}$ By Kruskal-Wallis test among Paget's disease sites 1, 2, and 3. 
Overall, our data indicate a foot-care need in patients with Paget's disease. Forty percent of the patients in this group required professional foot care in addition to those already receiving it. This need is not being met by National Health Service podiatry services. Indeed, five patients were previously referred by the consultant to the local podiatry service, but they were subsequently refused treatment. In part this reflects the limitation of the current provision of podiatric care to patients at highest risk, such as those with diabetes and rheumatoid arthritis, with the exclusion of the relatively healthy older population. However, it is known that in elderly patients, foot-care needs change across time, and there is evidence of the deleterious effect of withdrawal of footcare services on this patient group. ${ }^{13}$ In elderly patients, well-fitting footwear has been shown to improve comfort and mobility. ${ }^{14}$ Foot pain is also amenable to treatment with conservative measures, such as simple podiatric treatments, including debridement of hyperkeratosis, ${ }^{15,16}$ and this contributes to the reduction of foot pain, improving balance and increasing functional ability in older people.

In summary, these data suggest a high frequency of foot problems in patients with Paget's disease, although no higher than in previous studies of elderly patients. We hypothesized that patients with lowerlimb disease would have an increased risk of foot problems, but we found no clear evidence of increased foot pathology and symptoms in patients with lowerlimb disease compared with those with Paget's disease affecting the pelvis and upper limb only or both upper and lower limbs. However, the number of individuals with lower-limb disease only was small. Furthermore, we did not look specifically at the extent of lower-limb deformity, which might affect foot health. Further research is required on the impact of the extent of any femoral or tibial deformity on foot symptoms and pathology. Biomechanical studies of the forces and motion in the foot related to different degrees of femoral and tibial deformity might also help determine the impact of deformity on foot pathology.
Acknowledgment. This work was funded by a grant from the National Association for the Relief of Paget's Disease.

\section{References}

1. Collins DH: Paget's disease of bone: incidence and subclinical forms. Lancet 271: 51, 1956.

2. Platto MJ, O'Connell PG, Hicks JE, et al: The relationship of pain and deformity of the rheumatoid foot to gait and an index of functional ambulation. J Rheumatol 18: 38, 1991.

3. Budiman-Mak E, Conrad KJ, Roach KE: The Foot Function Index: a measure of foot pain and disability. J Clin Epidemiol 44: 561, 1991.

4. Stewart AL, WARE JE: Measuring Functioning and WellBeing: The Medical Outcomes Study Approach, Duke University Press, Durham, NC, 1992.

5. Van Gisbergen MJ, Dekker J, Zuijderduin W: Reliability of the diagnosis of impairments in survey research in the field of chiropody. Disabil Rehabil 15: 76, 1993.

6. Menz HB, Sherrington C: The Footwear Assessment Form: a reliable clinical tool to assess footwear characteristics of relevance to postural stability in older adults. Clin Rehabil 14: 657, 2000.

7. MunRo BJ, Steele JR: Foot-care awareness: a survey of persons aged 65 years and older. JAPMA 88: 242, 1998.

8. Frey C: Pain and deformity in women's feet . . . are shoes the cause? J Musculoskelet Med 12: 27, 1996.

9. White E, Mulley G: Footcare for very elderly people: a community survey. Age Ageing 18: 276, 1989.

10. BLACK JR, HALE WE: Prevalence of foot complaints in the elderly. JAPMA 77: 308, 1987.

11. Menz HB, Lord SR: Foot pain impairs balance and functional ability in community-dwelling older people. JAPMA 91: 222, 2001.

12. Helfand AE: Foot problems in older patients: a focused podogeriatric assessment study in ambulatory care. JAPMA 94: 293, 2004.

13. Campbell JA, Bradley A, Milns D, et al: Do "low risk" older people need podiatry care? preliminary results of a follow up study of discharged patients. Br J Podiatry 3: 39, 2000.

14. Finlay OE: Footwear management in the elderly care programme. Physiotherapy 72: 172, 1986.

15. Redmond A, Allen N, Vernon W: Effect of scalpel debridement on the pain associated with plantar hyperkeratosis. JAPMA 89: 515, 1999.

16. LANDorf KB, KeEnAN AM: Efficacy of foot orthoses: what does the literature tell us? JAPMA 90: 149, 2000. 